\title{
Human Resource Development in the Hotel Industry of Mauritius: Myth or Reality?
}

\author{
Girish Prayag ${ }^{1}$ and Sameer Hosany
}

[This a post-print version of the manuscript accepted for publication in Current Issues in Toruism. For full citation, refer to the published version - available using the doi: $10.1080 / 13683500.2013 .787051]$

${ }^{1}$ corresponding author: Girish Prayag, PhD, Department of Management, Marketing and Entrepreneurship, University of Canterbury, NZ; E: girish.prayag@,canterbury.ac.nz

\begin{abstract}
The purpose of this study is to identify the role, importance and outcomes attributed to HRD by line managers in the Mauritian hotel industry. Data were collected through in-depth interviews from a purposive sample of 135 hotel line managers. A two-step procedure was followed to analyse data. First, thematic analysis identified key themes in the textual data. Second, the artificial neural software CATPAC was used to generate interrelationships among the themes. Results show that HRD is related to organisational success, service quality improvements, sharing of knowledge and improvements in operational efficiency. Four key outcomes of HRD were identified: improvements in staff attitude, better teamwork, enhanced productivity and better service delivery. The findings indicate the prevalence of a need-driven approach to HRD and the link between HRD and corporate strategy is not clear. Results have implications for organizational and destination competitiveness.
\end{abstract}

Keywords: HRD, staff training, line managers, SIDS, Mauritius, neural network 


\section{Introduction}

Success of hotel operations is dependent on staff quality (Agut, Grau \& Peiro, 2003; Aksu, 2005; Hai-yan \& Baum, 2006). Lack of qualified personnel impacts on the service experience and affects future hotel patronage demand. Human resources (HR) remain an important determinant of tourism production and affects destination competitiveness (Murphy \& Price, 2005). Investing in Human Resource Development (HRD) allows organisations to enhance staff knowledge and capabilities (Leopold \& Harris, 2009), contributes to the provision of superior service quality and customer satisfaction (Aksu, 2005). Swanson (1996) defines HRD as "a process of developing and unleashing human expertise through organization development, personal training and development for the purpose of improving performance" (p.207). The general consensus is that HRD encompasses three components: learning, performance and change (Tseng \& McLean, 2008). In recent years, the concept of Strategic Human Resource Development (SHRD) has superseded HRD. Garavan (1991, p.19) defines SHRD as "the strategic management of training, development, and of management or professional education interventions, so as to achieve the objectives of the organization while at the same time ensuring the full utilization of the knowledge in detail and skills of individual employees". The concepts of HRD and SHRD are well entrenched in the Human Resources Management (HRM) and general management literatures. However, relatively fewer studies exist on HRD and/or SHRD in the hospitality setting (e.g. Esichaikul \& Baum, 1998; Cho, Woods, Jang \& Erdem, 2006; Chand \& Katou, 2007).

In addition, the majority of studies on HRM practices in the hospitality industry mainly focus on developed economies such as USA (Ingram \& Baum, 1997; Kalargyrou \& Woods, 2011), Spain (Agut, Grau \& Peiro, 2003), Australia (Davies, Taylor \& Savery, 2001; Jago \& Deery, 2004; Davidson, Timo \& Wang, 2010), Ireland (O’Neill, 1997; Baum \& Szivas, 2008; Nolan, Conway, Farrell \& Monks, 2010), New Zealand (Poulston, 2008), 
Germany (Langer, 2003) and UK (Maxwell, McDougall \& Clair, 2000; Watson, Maxwell \& Farquharson, 2007). However, with some exceptions (e.g. Browning, 2006; Fortanier \& van Wijk, 2010) scant research exists on HRM practices in the sub-Saharan African hospitality industry. In particular, HRD in Small Island Developing States (SIDS) remains poorly understood. Many factors impede on HRD in SIDS including poor quality of the human capital, and lack of government support. In addition, the International Research Foundation for Development (IRFD) notes despite SIDS recording human development in the medium to high range, migration of skilled nationals is very common (Neville \& Nishantha, 2004).

HRD has a positive long-term effect on organizational performance and bottom-line profits (Taylor \& Davies, 2004; Chand \& Katou, 2007; Tseng \& McLean, 2008). It actively contributes to the provision of superior service quality and customer satisfaction in the hospitality industry (Aksu, 2005). Yet, HRD activities in developing countries tend to focus on individual learning as opposed to organisational learning (Esichaikul \& Baum, 1998; Garavan, Heraty \& Barnicle, 1999). Instead of the workplace, the classroom is the learning arena and HRD is perceived as a reactive activity isolated from core organizational strategies (Garavan, Costine \& Heraty, 1995). Such HR orientations suggest a more 'traditional' approach to HRD in developing countries rather than a competency oriented or SHRD perspective (Garavan, Heraty \& Barnicle, 1999). For many SIDS, the challenge remains to develop a comprehensive and effective human resources base and to provide opportunties for training. HRD is an essential component in building institutional capacity of SIDS to deliver sustainable development (UN Department of Economic \& Social Affairs, 1998).

Accordingly, the objective of this study is to identify the perceived role, outcomes, drivers and challenges of HRD in the hotel industry in Mauritius. Mauritius, a small island developing state located off the eastern coast of South Africa, is a well-established tourist destination with a thriving hotel sector. According to the UNDP 2011 Human Development 
Report, Mauritius is ranked 77 out of 187 countries, putting the island in the high human development category. With a Human Development Index (HDI) of 0.728 , it is above the Sub-Saharan African average of 0.463 and ranked third in Africa behind Seychelles and Libya (UNDP, 2011). However, according to the 2011 World Development Indicators, the island spending on education and training is lower than the average for other countries in the high human development category. The paper's contribution to the literature is three-fold. First, the study identifies to what extent HRD is prevalent in the hotel industry of Mauritius. Second, we investigate the drivers and challenges of HRD. Finally, from a methodological perspective, the study demonstrates that combining thematic with content analysis enhances the credibility and trustworthiness of qualitative research.

\section{Literature Review}

\section{HRD in the Hospitality Sector \& Destination Competitiveness}

Both academics and practitioners advocate that successful hospitality operations require an understanding of the importance to invest in HRD (Ramos, Rey-Maquieira \& Tugores, 2004; Baum \& Szivas, 2008). Many traditional terms such as 'staff training and development' and 'work place education' have been used to refer to the set of formal organisational and individual practices designed to enhance the potential contribution of human resources to the organisation (Walton, 1999). In recent years, the terms 'workplace learning', 'human resource development' and 'strategic human resource development' are used to comprehensively explain individual and organisational learning processes (Garavan, 1991; Garavan, Morley, Gunnigle \& McGuire, 2002).

Over the years, HRD has been characterised in terms of various dimensions (see Table 1) (Garavan, Heraty \& Barnicle, 1999). In the hospitality literature, prior studies (e.g. (Nolan, 
2002; Davidson, McPhail \& Barry, 2011; Kalargyrou \& Woods, 2011) mostly focus on three aspects of HRD: i) the identification of core competencies required to meet present and future needs of the organization; ii) selection of the best delivery systems to enhance HR competencies; and iii) the management and delivery of training activities. Nolan (2002) notes the ad-hoc and reactive nature of HRD in the hospitality industry. Luoma (2000) describes this occurrence as 'need-driven' HRD - developmental activities are launched when a performance gap or training need is identified (see Table 1). However, the successful integration of HRD in business strategy and for enhanced business competitiveness, require a shift from 'need-driven' to 'capability-driven' HRD. Capability-driven HRD (Table 1) posits, "human behaviour is a critical source of sustained competitive advantage. Rather than relying on past or current performance, HRD should focus on the targeted future capabilities defined in strategy. HRD does not merely assist or support the company's progress but is a key means of executing strategy" (Luoma, 2000, p.146).

\section{[PLEASE INSERT TABLE 1 HERE]}

Similar to developed countries, island destinations and developing countries invest in staff training (formal and informal) and development as part of their HRD initiatives (Ramos, Rey-Maquieira \& Tugores, 2004; Fortanier \& van Wijk, 2010; Davidson, McPhail \& Barry, 2011). Many factors exist that negatively impacts the hospitality industry of SIDS to fully capitalise on the benefits of HRD. One such factor is the inherent characteristic of the hospitality industry. High employee turnover negatively impacts the knowledge base and influences long-term competitiveness (Hayes \& Ninemeier, 2009). In the case of Mauritius, the average staff turnover for the tourism industry is approximately $26 \%$, with lower levels for the most profitable hotels. At the destination level, the lack of a trained workforce negatively 
impacts on service quality and competiveness (Dwyer \& Kim, 2003). Government and other stakeholders need to appreciate the need for knowledge enhancement among tourism employees. Yet, workforce diversity, seasonality and weak internal labour markets are obstacles for implementing quality-effective HRD (Baum \& Szivas, 2008). For hoteliers willing to invest in HRD, the main benefits are employee loyalty, organizational competitiveness, better service quality and improved industry competitiveness (Davidson, McPhail \& Barry, 2011; Dwyer \& Kim, 2003; Hayes \& Ninemeier, 2009). For SIDS in particular, competitiveness of the hospitality industry is often tied to delivering superior service (Benitez, Martin \& Roman, 2007). Dube \& Renaghan (1999) identify variety of onsite hotel services and quality of staff as the most important determinants of hotel performance.

\section{Perceived Outcomes of Staff Training \& Development}

Generally, hotels tend to be people oriented and believe in HRD practices (Nolan, 2002). The value of HRD in the hospitality industry is closely associated with the positive outcomes it generates for the organization. Increased productivity is the most tangible positive outcome associated with HRD (Aksu, 2005). In their study of hotel establishments in Western Australia, Davies, Taylor and Savery (2001) found improvements in staff training had reciprocated effects on quality, productivity and reduced employee turnover. Kilic and Okumus (2005) showed that staff training and development was one of the five most important factors influencing productivity in small hotels. It also appears that there is a connection between organisations developing HRD policies and increased service quality through committed and satisfied staff (Kandampully, 2006; Luk \& Layton, 2004; Davidson, McPhail \& Barry, 2011). This effect seems to extend beyond the context of developed countries to developing countries as well. For example, Chand and Katou (2007) showed a 
positive and high correlation between staff training and development (induction and needs based training) and good service quality in the Indian hotel industry. However, this link between staff training and increased productivity and service quality may not always be clear (Nolan, 2002) given that such consequences of training may only materialise over a number of years while the cost of staff training and development has to be justified on a yearly basis. In addition, the causal link between HRD investment and organisational performance is also difficult to establish (Garavan, Heraty \& Barnicle, 1999) but evidence of this relationship exists in manufacturing firms (Luoma, 2000).

Also, HRD increases commitment to the organisation and employees are less likely to quit if training and development activities are appropriately mapped onto career advancement opportunities (Davies, Taylor \& Savery, 2001; Jago \& Deery, 2004). The hospitality industry has, in recent years, shifted from fulfilling skills gap to developing competencies (Kalargyrou \& Woods, 2011). Yet, this approach focuses all development activities on employee contribution to tactical as opposed to the strategic component of business strategy (Garavan, Heraty \& Barnicle, 1999). The HRD function has a strong cost-benefit focus and is concerned with budgets but has a more proactive stance than need-driven HRD (Garavan, Heraty \& Barnicle, 1999). The role of HRD is to support competitiveness in general (Luoma, 2000), rather than the adoption of a learning approach to strategy-proactively facilitating organisational change, nurturing learning within the workforce and facilitating line managers in the creation of a culture/climate of learning (Garavan, Heraty \& Barnicle, 1999).

HRD also plays an important role in improving employees' attitude, teamwork, selfawareness, and job satisfaction (Roel \& Swerdlow, 1999), resulting in improved competitiveness (Frabotta, 2000; Davies, Taylor \& Savery, 2001; Nolan, 2002). However, these outcomes can be readily observed if a capability-driven HRD approach is adopted, in which human behaviour is perceived as a critical source of sustained competitive advantage 
(Luoma, 2000). Development initiatives are needed to build competencies using a variety of HRD activities on the job and via external interventions. Competence building is systematic: formal, informal, structured and unstructured learning are fully integrated in the wider strategic HRM policies and plans (Luoma, 2000).

Previous research mainly suggests six positive outcomes of HRD in the hospitality sector: increased productivity, improved service quality, reduced employee turnover, increased staff commitment, improved employee behaviour and job satisfaction, and improved business performance. In addition, the literature on HRD in manufacturing firms (e.g. McCracken \& Wallace, 2000; Luoma, 2000; Tseng \& McLean, 2008) suggests that HRD can lead to other positive outcomes such as shaping organizational missions and goals, influence corporate culture, strategic partnerships with HRM and line managers and shape future HRD strategies, policies and plans.

However, in the hospitality sector, HRD is almost exclusively related with provision of solutions for immediate work problems rather than the long-term development of people and the creation of a learning organisation (Nolan, 2002). As a result, this can explain differences in outcome associated with HRD practices in the hospitality sector and manufacturing firms. Where a more strategic approach is adopted, the significant driving force still remains staff training (Nolan, 2002). The unique social and cultural context of developing countries and small islands, may lead to the role and outcomes of HRD in the hospitality sector being different to those previously identified in the literature (Ramos, ReyMaquieira \& Tugores, 2004; Chand \& Katou, 2007).

\section{Methods}

\section{Study Setting}


The study was conducted among hotel line managers in Mauritius. Three large domestic hotel groups (New Mauritius Hotels Ltd., Sun Resorts Ltd., and Naiade Resorts Ltd.) dominate the Mauritius hotel industry. As of 2009, 102 hotels were in operation with a total capacity of 11,456 rooms. Of these hotels, $30 \%$ are owned/operated as small and medium enterprises (AHRIM Annual Report, 2009/2010). The hotel industry generated direct and indirect employment for around 150,000 people, representing $28.5 \%$ of the total workforce on the island or 1 in every 3.5 jobs (WTTC, 2010). Mauritius is one of the few success stories in Africa for initiating HRD through collaborative partnerships between the government and the private sector. Hotel employers, through various government initiatives are encouraged to invest in staff development. For example, the Human Resource Development Council (HRDC) offers training grants and companies can recover up to $75 \%$ of their training costs (African Economic Outlook, 2008). To qualify for the grant, hotels are required to conduct training programmes in-house or through approved institutions such as the Sir Gaetan Duval Hotel School.

The HRDC has also launched other initiatives such as the National Human Resource Development Plan (NHRDP) and promotion of lifelong learning and employability to coordinate human capital development across various targeted sectors, including tourism (www.hrdc.mu). Past research indicates continuous training as an important facet of career development in hotels (Ladkin \& Juwaheer, 2000). Investment in HRD remains a high priority on management agenda for delivering excellent service in hotels (Juwaheer, 2006). Yet, little is known on how HRD is integrated with other managerial functions (in other words SHRD) in hotels and the effectiveness of current HRD initiatives.

\section{Research Design and Data Collection}


Similar to Ingram and Fraenkel (2006), a qualitative approach in the form of semistructured interviews was adopted to understand the role, importance and challenges of HRD in the hotel industry of Mauritius. To maximise participants engagement, we designed three broad questions: 1) What activities do you associate with HRD; 2) How important is HRD for your department at the hotel?; and 3) What improvements have you seen over the years in your department due to HRD initiatives? The target population was line managers from three departments: food and beverage, guest-relations/front-office and housekeeping. Previous research (e.g. Davies, Taylor \& Savery, 2001; Nolan, Conway, Farrell \& Monks, 2010) support the importance of training in these three areas. Given that line managers are central to the process of workplace learning and in supporting both individual and organisational learning processes (Garavan, Morley, Gunnigle \& McGuire, 2002), it is reasonable to investigate their perceptions of HRD.

Line managers encompass departmental heads and supervisors (Hales, 2005). We specifically targeted line managers actively involved in staff training and development. The study adopts a purposive sampling method and focuses on a small number of hotels. 135 line managers (see Table 2) were interviewed from a convenience sample of 50 hotels. The smallest hotel in the sample had 14 rooms and the largest hotel had 349 rooms. From Table 2, the majority of participants $(77.7 \%)$ were males. Around half $(48.9 \%)$ of participants were in the age group 36 to 45 years. Respondents held supervisory (housekeeping, bar) and managerial positions (executive chef, bar manager, housekeeping). Each interview was conducted face-to-face, lasted approximately one hour, was tape-recorded and later transcribed.

[PLEASE INSERT TABLE 2 HERE]

\section{Data Analysis}


The interview transcripts were analysed using a two-step procedure. First, thematic analysis was used to identify key themes in the data. Following Braun and Clarke's (2006) guidelines, we generated a 'thematic map'. The emerging themes were then supported with selection of vivid extracts from the transcripts. In the second step of data analysis, transcripts for each question were entered into a software tool. The use of qualitative software in analysing data has galvanised momentum in the hospitality literature. Lockyer (2005) successfully uses TextSmart to understand the factors influencing the selection of hotel accommodation. Gross and Huang (2011) employs NVivo to understand internationalisation prospects for Chinese domestic hotel firms. Using ATLAS-ti, Kalargyrou and Woods (2011) attempt to better understand training competencies required in the US hospitality industry. For the purpose of this research, the CATPAC software was utilised to analyse the data. CATPAC identifies interrelationships among concepts in a dataset and generates numeric values of association (Ryan \& Cave, 2005).

\section{Findings}

\section{Importance of HRD}

Line managers $(n=74)$ overwhelmingly associate HRD with the provision of staff training, with emphasis on individual learning as opposed to organizational learning. Hotels have a strong preference for on-the-job training as shown in the following quote:

"There is no best mode of training other than on the job training. I joined this hotel 11 years ago, I have learnt everything here. It is better for employees, they learn more quickly, they assimilate better in real work conditions"

Housekeeping Supervisor 
Findings reveal five plausible reasons for managers' support of on-the-job training. First, it is efficient, less costly and employees assimilate more quickly in real work conditions. Second, on-the-job training offers opportunities for interactions and is an effective way for team building, especially among new recruits. Moreover, management exerts greater control over the quality of training. On-the-job training is flexible (offered during off-peak hours) and thus puts little pressure on busy work schedules. Finally, on-the-job training enables trainers to identify potential future leaders within the organisation. Findings indicate an operational rather than strategic approach to staff training and development.

In addition, 25 line managers were in favour of combining methods of training for improved effectiveness of training, indicative of a divergence among hoteliers in perceptions of staff development. Others associated HRD with improved recruitment and selection of employees $(n=22)$ and developing career paths $(n=46)$. Only 2 interviewees associated HRD with organisational learning. Findings clearly point to the practice of HRD rather than SHRD in Mauritius. The poor performance of Mauritius on investment in tertiary education and training can be attributed to this occurrence.

In terms of the relative importance of HRD in the organization, thematic analysis identifies four major themes: (1) HRD is a challenge but key to organizational success; (2) HRD is associated with service quality improvements; (3) HRD is the sharing of knowledge and skills among employees; and (4) HRD contributes to operational efficiency.

\section{Theme 1: HRD is a Challenge but is Key to Organizational Success}

The first theme relates to the perception that HRD is a challenging task. Line managers reveal the constant need for innovative training practices in order to keep pace with changing international standards. HRD is the solution to operational work place problems, as evidenced in the quote below: 
"Training is the primary challenge in the food and beverage department. We constantly need to update staff skills as international culinary standards change and guests' preferences and tastes change. This help to create an organisational culture that provide a high priority in providing quality service to the guest. We need to constantly invest in the people."

Bar \& Restaurant Manager

HRD is also seen as a major contributing factor to organizational success, highlighting its strategic role in the organization. This is not surprising given a fundamental function of HRM practices is staff development and training for better organisational performance (Davies, Taylor \& Savery, 2001). For example one manager mentioned:

"Training is very important for our department in the sense that it enables employees to understand guests and other employees. This enables them to improve their knowledge, skill, attitude, and better communicate with others. All hotels are different in the way they treat customers and through training we are able to be better and move towards success of the hotel."

Front-office Manager

Theme 2: HRD is Associated with Service Quality Improvements

From the interview transcripts, it was evident that staff training and development initiatives were strongly related to service quality improvements. For example, training initiatives for the food and beverage department in the last few years have centred on customer service, handling guest complaints, HACCP accreditation, and selling techniques in restaurant and bar service. As for the front-office department, training initiatives have been related to reservation technologies, handling guest complaints, customer service and language training. In the housekeeping department, a similar trend can be seen with training in areas such as room cleaning, minibar service training, laundry service and customer service. This 
emphasis on service quality improvements can be related to the positioning of the island in the luxury segment and can be seen in the quote below:

"Training occupies a great place in the front office department and this forms an integral part of the hotel, if not one of the most important activities. Our guests know us for our service standards, we want to constantly improve through training,... we get international trainers to do that. If we don't meet guests' expectations, they don't come back. Our guests expect service excellence,...we offer excellence on this paradise island. This is how Mauritius is marketed."

Front-office Manager

Yet, the emphasis on developing operational skills as opposed to competencies indicates a needs-driven approach to HRD in Mauritius. HRD is mostly associated with training methods and its effectiveness. The focus is on addressing skills gap, as opposed to long-term development of people. This issue is also prevalent in other industries. The NHRDP for Mauritius emphasises the need for developing proactive rather than reactive HRD policies.

\section{Theme 3: HRD is Sharing of Knowledge and Skills}

One important aspect of HRD for line managers was the opportunity for sharing knowledge and skills with front-line employees. Line managers got involved in staff training for a variety of reasons including, sharing of experiences to motivate staff, ensuring that employees understand job responsibilities and quality standards, and for their own career development. Line managers also train employees so that they are able to make their own decisions and assume increasing responsibility in the organization. This leads to improved confidence, higher productivity, and more team work among front-line employees as exemplified in the quote below. 
"Our clients are becoming more demanding therefore, knowledge (technical and academic) must be adapted, service rendered must be updated and always better, customer relationships must be to a satisfactory level. I joined this hotel 15 years ago and today I am the Housekeeping executive. Training is very important, and part of my job is to train others....i share my experiences and achievements with them. Housekeeping is a difficult job and they (employees) need to be constantly motivated.... i make sure they know what they have to do in the shortest time e.g. to clean a room."

Housekeeping Executive

Another respondent pointed:

"Training helps me to impart an international and local knowledge that others may not have. I spent 5 years working in Dubai before coming back and $i$ do some coaching for every employee of this department. It is an essential thing contributing to success of the hotel. I enjoy this aspect of my job, I can share my own experiences with others...it (training) encourages me to give the best of myself for my staff."

\section{Executive Chef}

The notion of individual learning is omnipresent in the above quotes but organizational learning seems nascent as well, whereby sharing of knowledge by line managers is considered necessary for employee and organizational success. The ability of line managers to share their international experiences with other employees is considered a vital component of HRD.

\section{Theme 4: HRD Contributes to Operational Efficiency}

This theme beckons that the value of staff training and development is related to line managers' perceptions of improvements in operational efficiency. Some of these line managers mentioned that their hotels are already accredited ISO 9000 while others are going through the process. Therefore, employees are trained so that they can meet the demands required by these certifications. This emphasis on operational efficiency seems to be driven 
by increased competition from other island destinations such as Seychelles and Maldives and therefore, the need to differentiate hotels in Mauritius by offering better service quality and being more efficient. For example one participant mentioned:

"It (training) is about bringing change and improvements in the way we do things. It is one of the key factors that help this department achieve its objectives. Without training it is almost impossible to achieve success. My manager wants the staff to be more efficient (e.g. reduce breakage in F\&B). We need to turn around tables more quickly in the 3 restaurants we have here... we need to sell more drinks. Profitability is important in difficult times and we need to become more efficient in the way we do things."

Assistant F\&B manager

\section{Key Outcomes of HRD}

In terms of the outcomes of $\mathrm{HRD}$, respondents perceived five main changes occurring both within the organisation and among employees. Each of them is explained below.

\section{Outcome 1: Improvements in Staff Attitude}

Many line managers mentioned that improvements in general staff attitude over the years were the primary consequence of training and development. As one line manager said:

"The young ones (staff) are fresh from school or hotel school, sometimes they lack professionalism, discipline and being able to work together. Through the courses they follow here, we are able to get them in no time to behave appropriately and to be considerate to each other. Lots of team work involved in $F \& B$ and they should be able to integrate the existing team"

F\&B manager

Employee behaviour (EB) seems to be an important element of line managers' responsibilities, however, it is not clear whether EB is a critical source of competitive 
advantage. The right EB merely assists or supports the hotel's progress at the tactical level. Also, line managers perceived that the education system is unable to adequately prepare young people to enter the hospitality sector.

\section{Outcome 2: Higher Productivity}

By far staff training and development in Mauritius has led to productivity enhancements. This is a key goal of the NHRDP for Mauritius with a specific emphasis on productivity vis-à-vis competitors. Hotel line managers mentioned that through continuous training, they have been able to create a more efficient and effective workforce across departments. Some mentioned that in their departments, productivity has increased over the years by more than $50 \%$ as shown in the quote below. Hence, a positive relationship exists between investment in HRD and organisational performance for line managers.

"We (line managers) have seen improvements of more than 50\% in productivity over the last five years. Employees are now very confident in their job, they are more productive and they have learnt the value of good team work within the organization. Their attitude to the job has changed and it is now more easy for them to deliver a better service and to perform the job better than before."

Assistant F\&B manager

\section{Outcome 3: Better Teamwork}

Another positive benefit of staff training and development has been better teamwork among front-line staff. Line managers have been able to cultivate a culture of positive attitude towards the workplace and fellow employees as well as team spirit among staff. Also, the reporting relationships between line managers and front-line employees are perceived to have improved due to better communication and a stronger sense of belonging to the hotel. HRD efforts cannot ignore the prevailing and desired cultures of an organization in the learning 
process (Tseng \& McLean, 2008). Developing the right workplace culture is important for hotels in Mauritius as one supervisor commented:

"Staff training has enabled us to cultivate a positive attitude, show a sense of belonging, always be ready to help customers and other employees. These create better morale among staff, they feel more confident in their job. There is better team spirit, more professional employees, and guests are very happy."

Assistant Housekeeping Executive

The quote also shows the interrelationships between the previous factors and teamwork. The service adage that happy employees lead to happy customers seems to be valid in this context too.

Outcome 4: Improvements in Service Delivery

Many line managers mentioned that through HRD they have been able to improve service delivery in their departments. Respondents noted an increase in positive comments left on guest cards and an improvement in perceived service quality evaluations among tourists. As one participant mentioned:

"Quality of work has known an improvement over the years, service delivery is better. For example, in the front office we have seen guest comments improving by more than $80 \%$ in the last few years. Employees are more positive to offer a higher quality service. They are more conscious about the importance of service quality and they try to offer the best quality of service. And the employees have become more confident and productive."

Front-office supervisor

Outcome 5: Better Motivated Employees 
Related to the previous outcomes, line managers also mentioned that another positive benefit of HRD has been an increase in motivation levels among employees resulting in greater teamwork and better communication. Staff training and development helps to develop closer emotional bond and improve supervisor-supervisee relationship. The following quote is a good exemplar:

"Employees are demonstrating a more positive attitude towards the hotel. Employees are more motivated and they work towards a number of goals and objectives. There is greater acceptance of these goals and they understand their job responsibilities better. We communicate better and they understand clearly how they will be evaluated at the end of the year."

Assistant F\&B manager The quote confirms the importance of setting specific goals and objectives for HRD plans and policies to succeed (Garavan, Heraty \& Barnicle, 1999; Tseng \& McLean, 2008).

\section{Content Analysis using CATPAC}

In qualitative research, it is important to establish the credibility of interpretation using a triangulation of data analytical techniques (Jennings, 2001). Accordingly, we use the CATPAC software (Woelfel, 1998) to further validate and quantify the findings derived from thematic analysis. CATPAC is an artificial neural network software for reading text. The software is able to identify the most important words in textual data and determine any patterns of similarity. Prior to using CATPAC, a "data smoothing" procedure was carried out on the textual data (Stepchenkova, Kirilenko \& Morrison, 2009). The process involved reducing the redundancy of words, creating standards for the tense of verbs, standardising form of nouns, and creating simplified labels and key phrases (Ryan \& Cave, 2005). A more detailed review of this procedure can be seen elsewhere in the literature (e.g. Woelfel, 1998; Ryan \& Cave, 2005; Prayag \& Ryan, 2011). The software produces a variety of outputs: word 
counts, frequency rankings and dendograms. The latter is generated using cluster analysis algorithm.

Using the word frequency ranking function of CATPAC to identify key terms, results show (see Figure 1) HRD was associated with the words 'important' $(n=72)$ and 'success' ( $n=60)$. Such findings further establish the relevance of Theme 1 (HRD is a challenge but is key to success) as derived from earlier thematic analysis. Similarly, the words 'service quality' ( $n=17)$ and 'knowledge' $(n=60)$ confirmed Theme 2 (HRD is associated with service quality improvements) and Theme 3 (HRD is sharing of knowledge and skills) respectively. Finally, the validity of Theme 4 (HRD contributes to operational efficiency) is further reinforced with the emergence of the words 'continuous-process' $(n=26)$ and 'daily-activities' $(n=45)$

[PLEASE INSERT FIGURE 1 HERE]

Concerning the outcomes of HRD, textual responses to the question: "What improvements have you seen over the years in your department due to staff training?" were entered in CATPAC. A dendogram was generated using Ward's clustering method. The dendogram depict strong and weak relationships between a set of words (Woelfel, 1998). Results (Figure 2) reveal the existence of four clusters. Cluster 1 shows a strong association between five words namely, 'deliver', 'positive', 'front', 'guest', 'comments'. Reviewing the interview transcripts, a main outcome of HRD is clearly improved service delivery that in turn leads to positive appraisals of front-line staff. Cluster 2 consists of four words ('professional', 'efficient', 'big' and 'job') and is associated with higher productivity. As a result of staff training and development, employees became more efficient and professional in their job. Cluster 3 shows a strong association between words 'perform', 'delivery' and 'team'. Findings suggest training is a catalyst for teamwork, leading to superior performance and 
service delivery. Cluster 4 reveals an association among eight words: 'attitude', 'better', 'employees', 'improvement', 'work', 'confident', 'quality', and 'service'. Consistent with prior thematic analysis, findings reveals staff training and development leads to improvements in attitude, employee confidence and perceptions of service quality.

[PLEASE INSERT FIGURE 2 HERE]

\section{Discussion and Implications}

The main objectives of this paper were i) to understand the role, importance and challenges associated with HRD; and ii) to identify perceived outcomes of HRD practices. The results indicate that HRD is important for both government and hoteliers but the latter mainly associate the concept with staff training and development practices, indicative of early stages in the HRD cycle - a need-driven approach to HRD (Luoma, 2000). The focus of line managers is on immediate outcomes that are generated by implementing core HRM strategies (recruitment, selection and training) and maintaining the desired level of skills among employees. Most of the common dimensions of HRD (see Table 1) identified in other context do not replicate in Mauritius. HRD is perceived as a tactical component of HRM rather than a strategic means of executing business strategy. The differences in HRD values and activities can be attributed to the structure of the hospitality industry in Mauritius. Three large domestic hotel groups and SMEs dominate the industry. Hotel size, ownership structure, length of operation and different departmental functions may account for the divergent results.

Some of the findings align with contemporary HRM literatures confirming the role of training as a catalyst for business performance (e.g. Garavan, Heraty \& Barnicle, 1999; Davidson, McPhail \& Barry, 2011; Kalargyrou \& Woods, 2011). The findings highlight the 
need for small island developing states to remain competitive and on par with international practices in hospitality management. However, the focus on upgrading skills rather than developing staff competencies and immediate outcomes as opposed to long-term benefits have consequences for the competitiveness of hotels and the tourism industry. In comparison to other countries in Africa with similar HDI, Mauritius has a relatively low level of investment in education and training. In the long-term, this situation will have a detrimental impact on the positional advantages of the island's tourism and hospitality industry. The NHRDP for Mauritius has specifically outlined this issue as part of its strategic plan. Tourism has now found its way into secondary school curriculum as a measure to address some of these issues.

Furthermore, the emphasis on service quality improvements as an important outcome of HRD is consistent with previous research (e.g. Kandampully, 2006; Luk \& Layton, 2004; Aksu, 2005). Through service excellence, island destinations can differentiate their hospitality products, ensuring the survival of the hotel sector. Service quality remains a key determinant of destination competitiveness (Dwyer \& Kim, 2003). Despite many hotels establishing a reputation for service excellence, the role of HRD seems detached from the broader goal of organizational learning. Organizational learning can be fostered in hotels by the creation of a culture, within which a range of training, development and learning strategies correspond to the overarching corporate strategies (McCracken \& Wallace, 2000).

In addition, findings suggest that line managers can act as a change agent, coach, and communicator in the organization. Developing the competence of line managers and their subordinates is vital to successful implementation of HRD and SHRD (Garavan, 1991; Tseng \& McLean, 2008). The devolving HR activities such as employee motivation, training, and empowerment to line managers are in par with international trends (see Watson, Maxwell \& Farquharson, 2007). Line managers are fulfilling greater HR responsibilities and therefore 
have the ability to positively influence employee behaviour and organisational performance (Hutchinson \& Purcell, 2003). If line managers are adequately trained as 'trainers', they can also contribute to HRD functions such as policy formulation, training plans and advising on broader HRM strategies (Gibb, 2003). Hence, for long-term sustainability of the hotel sector in Mauritius, line managers should be considered as key stakeholder in the HRD process.

Overall, the outcomes of HRD identified in this study are consistent with previous studies in the hospitality sector (e.g. Roehl \& Swerdlow, 1999; Kandampully, 2006; Aksu, 2005; Chand \& Katou, 2007) but differ from those identified in other industries (McCracken \& Wallance, 2000; Tseng \& McLean, 2008). The lack of a clear link between HRD and corporate strategy may explain these results (Garavan, 1991; Nolan, 2002). Need-driven HRD lacks integration of HRD practices with organization missions and goals (Luoma, 2000; Tseng \& McLean, 2008). Despite HRD practices such as line manager commitment and involvement, recognition of culture, and emphasis on evaluation were identified in hotels of Mauritius, these do not lead to outcomes identified in manufacturing firms such as shaping of organizational missions and goals, strategic partnerships with HRM and line managers, and ability to influence corporate culture (McCracken \& Wallace, 2000; Tseng \& McLean, 2008). For Mauritian hotels, the lack of organizational learning is a barrier preventing the shift from HRD to SHRD. To foster organizational learning, a change in mind-set of decision-makers and employees is needed, replacing the current short-term emphasis on developing hard skills with a more holistic approach to human capital development. For this to happen, changes in the education system and perhaps in the Mauritian society as a whole is necessary.

The education system in Mauritius has traditionally been teacher-centred with little emphasis on students' interests. Recent reforms on curriculum development highlight the need for students to develop an affinity to their socio-cultural environment and teamwork as being crucial for self-development. However, such reforms have received much resistance 
from unionised teachers. Teamwork is not an integral part of the Mauritius education system and teachers do not see its value (National Report, 2008). School leavers enter the work place with a strong mind-set of individual as opposed to team achievements. Such attitude hampers the future development of human capital in Mauritius. Likewise, the labour market in Mauritius has its own idiosyncrasies preventing the implementation of HRD in a similar way as in western countries. For example, the structure of many Mauritian organizations including hotels, mimics that of extended families with the 'head' role exclusive to the oldest male. Accordingly, management styles tend to be patriarchal and autocratic with little or no delegation of job tasks and responsibilities (Lee-Ross, 2005). Autonomy and empowerment while valued are not necessarily embedded in day-to-day operational activities of hotels. Therefore, employees are often 'doers' as opposed to 'thinkers'. It is plausible that the colonial heritage of Mauritius instigates a distinct type of leadership and management style, organisational structure and worker profile (Lee-Ross, 2005).

From a methodological standpoint, results illustrate the usefulness of combining thematic and content analysis in dealing with textual data. In particular, the artificial neural network software CATPAC facilitates content analysis and adds more credence to results obtained from thematic analysis. CATPAC examines textual data for patterns of similarity, develop categories and provides numeric values of association among related concepts. The software, through its clustering algorithm, is better at revealing linkages between 'themes' than thematic analysis alone (Stepchenkova \& Morrison, 2008). In addition, the study reinforces Stepchenkova, Kirilenko \& Morrison (2009) proposition for using computerassisted software in tourism and hospitality research in order to discern meaning from rich textual data.

\section{Limitations and Future Research}


To conclude, the study contributes to the lack of qualitative studies in understanding hospitality HRM issues such as the importance and outcomes of HRD for a small island developing state in sub-Saharan Africa. However, the study entails limitations, which offer avenues for future research. First, the results cannot be generalised to the entire hotel sector in Mauritius. Future studies can extend the results by adopting a quantitative approach. Second, only the views of line managers were included in this study. For a more comprehensive understanding of HRD, future studies should triangulate the views of front-line staff and top management to understand their commitment to individual and organizational learning and how these influence organizational and destination competitiveness. Another area of research would be to investigate the influence of organisation culture, hotel size, ownership structure, and length of operation on HRD practices and organisational performance in small island economies. Likewise, comparing HRM and HRD practices in different islands would improve our understanding of this contemporary management function in the hospitality industry. 
Table 1: Dimensions, Need vs. Capability-driven HRD

\begin{tabular}{|c|c|c|}
\hline Generic Dimensions of HRD & Need-driven HRD & Capability-driven HRD \\
\hline $\begin{array}{l}\text { *HRD is intrinsically related to } \\
\text { overall business strategy \& } \\
\text { competitive advantage } \\
\text { *HRD is perceived as an } \\
\text { investment in HR capability rather } \\
\text { than an employment cost } \\
\text { *HRD is concerned with change at } \\
\text { both organizational \& personal } \\
\text { levels } \\
\text { *HRD views the employee in a } \\
\text { 'holistic' way } \\
\text { *HRD is concerned with } \\
\text { identifying and enhancing the core } \\
\text { competencies required at each level } \\
\text { to meet organizational present and } \\
\text { future objectives } \\
\text { *HRD focuses on the management } \\
\text { and delivery of training activities } \\
\text { within the organization } \\
\text { *HRD selects the best delivery } \\
\text { systems designed to enhance HR } \\
\text { competencies } \\
\text { *HRD is concerned with } \\
\text { organizational \& individual } \\
\text { learning } \\
\text { *HRD consists of a set of generic } \\
\text { activities associated with learning } \\
\text { *HRD is concerned with how well } \\
\text { HR strategies are reinforced by and } \\
\text { reinforce other HR strategies }\end{array}$ & $\begin{array}{l}\text { *HRD is reactive in nature } \\
\text { *Human behaviour is not a critical } \\
\text { source of competitive advantage } \\
\text { *Training requirements and skills } \\
\text { development follow from } \\
\text { macro/micro business environment } \\
\text { considerations of strategy } \\
\text { *Task of HRD is to assist strategy } \\
\text { implementation by maintaining the } \\
\text { desired level of competence }\end{array}$ & $\begin{array}{l}\text { *Human behaviour is a critical } \\
\text { source of sustained competitive } \\
\text { advantage } \\
\text { *HRD focuses on targeted future } \\
\text { capabilities defined in strategy as } \\
\text { opposed to past or current } \\
\text { performance } \\
\text { *HRD is a key means of executing } \\
\text { strategy }\end{array}$ \\
\hline
\end{tabular}

Source: Adapted from Garavan, Heraty \& Barnicle (1999) \& Luoma (2000) 
Table 2: Profile of Participants

\begin{tabular}{|l|c|c|l|c|c|}
\hline Gender & Freq. & $\mathbf{\%}$ & Job Position & Freq. & \% \\
\hline Male & 105 & 77.7 & Supervisor & 40 & 29.7 \\
\hline Female & 30 & 22.3 & Assistant Manager & 42 & 31.1 \\
\hline Age & & & Manager & 53 & 39.2 \\
\hline $26-35$ years old & 47 & 34.8 & Department & & \\
\hline $36-45$ years old & 66 & 48.9 & Food \& Beverage & 45 & 33.3 \\
\hline $46-55$ years old & 22 & 16.3 & Front Office & 45 & 33.3 \\
\hline & & & House keeping & 45 & 33.4 \\
\hline
\end{tabular}


Figure 1: Thematic map based on frequency counts of most utilised words

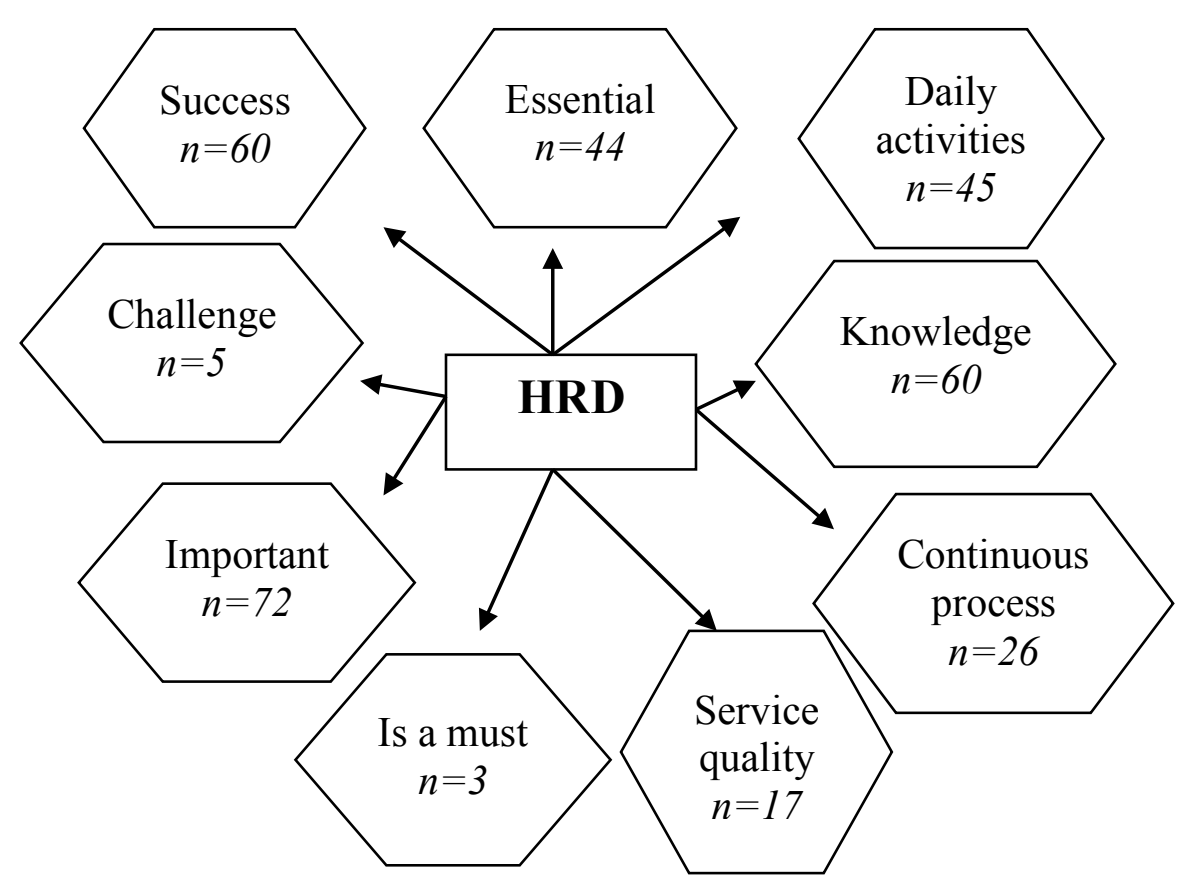


Figure 2: Dendogram for the outcomes of human resource development

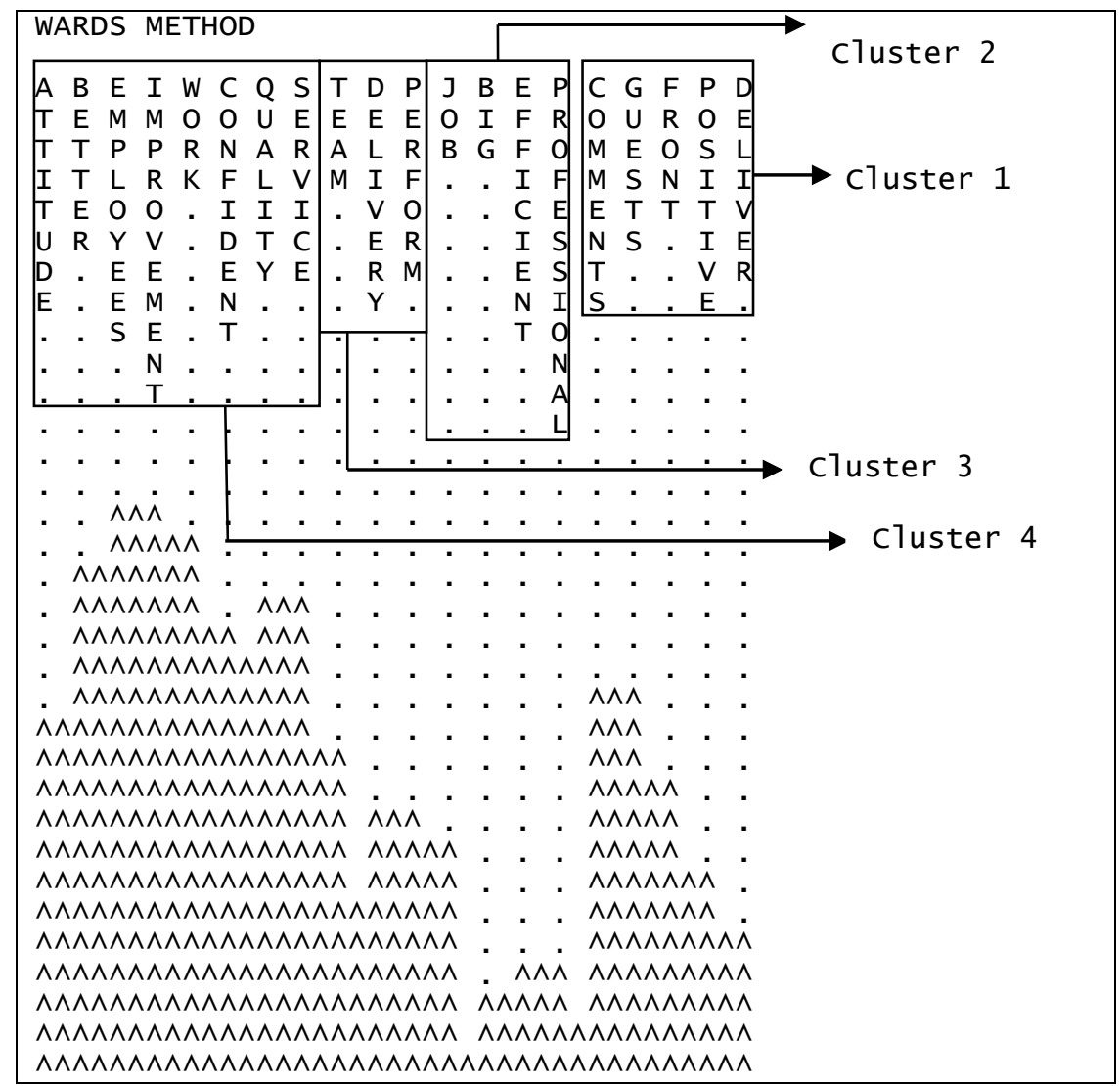




\section{Acknowledgment}

The authors would like to thank Jean-Alain Noel, University of Mauritius for facilitating data collection and the three anonymous reviewers for their insightful comments and suggestions.

\section{References}

African Economic Outlook (2008). Report published by the Organisation for Economic Cooperation and Development.

African Economic Outlook (2012). Report published by the Organisation for Economic Cooperation and Development.

Agut, S., Grau, R., \& Peiro, J.M. (2003). Competency needs among managers from Spanish hotels and restaurants and their training demands. Hospitality Management, 22, 281295.

Aksu, A.A. (2005). Defining training needs of five-star hotel personnel: an application in the Antalya region of Turkey. Managerial Auditing Journal, 20(9), 945-953.

Association des Hôteliers et Restaurateurs de L'ile Maurice (AHRIM). Annual Report 2009/2010. Published by AHRIM, Port-Louis: Mauritius.

Baum, T. (2007). Human resources in tourism: still waiting for change. Tourism Management, 28, 1383-1399.

Baum, T., \& Szivas, E. (2008). HRD in tourism: A role for government? Tourism Management, 29, 783-794.

Benitez, J.M., Martin, J.C., \& Roman, C. (2007). Using fuzzy number to measure service quality in the hotel industry. Tourism Management, 28, 544-555.

Braun, V., \& Clarke, V. (2006). Using thematic analysis in psychology. Qualitative Research in Psychology, 3(1), 77-101. 
Browning, V. (2006). The relationship between HRM practices and service behaviour in South African service organizations. International Journal of Human Resource Management, 17(7), 1321-1338.

Chand, M., \& Katou, A.A. (2007). The impact of HRM practices on organizational performance in the Indian hotel industry. Employee Relations, 29(6), 576-594.

Cho, S., Woods, R.H., Jang, S.C., \& Erdem, M. (2006). Measuring the impact of human resource management practices on hospitality firms' performance. Hospitality Management, 25, 262-277.

Davidson, M.C.G., Timo, N., \& Wang, Y. (2010). How much does labour turnover cost? A case study of Australian four-and five-star hotels. International Journal of Contemporary Hospitality Management, 22(4), 451-466.

Davidson, M.C.G., McPhail, R., \& Barry, S. (2011). Hospitality HRM: past, present and the future. International Journal of Contemporary Hospitality Management, 23(4), 498516.

Davies, D., Taylor, R., \& Savery, L. (2001). The role of appraisal, remuneration and training in improving staff relations in the Western Australian accommodation industry: a comparative study. Journal of European Industrial Training, 25(7), 366-373.

Dube, L., \& Renaghan, L. M. (1999). How hotel attributes deliver the promised benefitsguests' perspectives on the lodging industry's functional best practices (Part II). The Cornell Hotel and Restaurant Administration Quarterly, 40(5), 89-95.

Dwyer, L., \& Kim, C. (2003). Destination competitiveness: determinants \& indicators. Current Issues in Tourism, 6(5), 369-414.

Esichaikul, R., \& Baum, T. (1998). The case of government involvement in human resource development: a study of the Thai hotel industry. Tourism Management, 19(4), 359370. 
Fortanier, F., \& van Wijk, J. (2010). Sustainable tourism industry development in subSaharan Africa: consequences of foreign hotels for local employment. International Business Review, 19(2), 191-205.

Frabotta, D. (2000). Human resources director praises culture at Marriott. Hotel \& Motel Management, 215(19), 136.

Garavan, T.N. (1991). Strategic human resource development. Journal of European Industrial Training, 15(1), 17-30.

Garavan, T.N., Costine, P., \& Heraty, N. (1995). The emergence of strategic HRD. Journal of European Industrial Training, 19(10), 470.

Garavan, T.N., Heraty, N., \& Barnicle, B. (1999). Human resource development literature: current issues, priorities and dilemmas. Journal of European Industrial Training, 23(4/5), 169-179.

Garavan, T.N., Morley, M., Gunnigle, P., \& McGuire, D. (2002). Human resource development and workplace learning: emerging theoretical perspectives and organizational practices. Journal of European Industrial Training, 26(2/3/4), 60-71.

Gibb, S. (2003). Line manager involvement in learning and development: small beer or big deal. Employee Relations, 25(3), 281-293.

Gross, M.J., \& Huang, S. (2011). Exploring the internationalization prospects of a Chinese domestic hotel firm. International Journal of Contemporary Hospitality Management, 23(2), 261-274.

Hai-yan, K., \& Baum, T. (2006). Skills and work in the hospitality sector: The case of hotel front office employees in China. International Journal of Contemporary Hospitality Management, 18(6), 509-518.

Hales, C. (2005). Rooted in supervision, branching into management: continuity and change in the role of the first line manager. Journal of Management Studies, 42(3), 471-506. 
Hayes, D K., \& Ninemeier, J. D. (2009). Human Resource Management in the Hospitality Industry. New Jersey, NJ: Wiley \& Sons

Hutchinson, S., \& Purcell, J. (2003). Bringing policies to life: the vital role of front-line managers in people management. London: CIPD

Ingram, P., \& Baum, J.A.C. (1997). Chain affiliation and the failure of Manhattan hotels, 1898-1980. Administrative Science Quarterly, 42, 68-102.

Ingram, A., \& Fraenkel, S. (2006). Perceptions of productivity among Swiss hotel managers:

A few steps forward? International Journal of Contemporary Hospitality Management, 18(5), 439-445.

Jago, L.K., \& Deery, M. (2004). An investigation of the impact of internal labour markets in the hotel industry. The Services Industry Journal, 24(2), 118-129.

Jennings, G. (2001). Tourism Research. Australia: John Wiley \& Sons.

Juwaheer, T.D. (2006). Using service quality expectations as a criterion to segment international tourists in the hospitality industry: an outlook of hotels of Mauritius. Journal of Travel \& Tourism Marketing, 21(2/3), 1-18.

Kalargyrou, V., \& Woods, R.H. (2011). Wanted: Training competencies for the $21^{\text {st }}$ century. International Journal of Contemporary Hospitality Management, 23(3), 361-376.

Kandampully, J. (2006). Services Management: The New Paradigm in Hospitality. Upper Saddle River, NJ: Prentice Hall.

Kilic, H., \& Okumus, F. (2005). Factors influencing productivity in small island hotels: evidence from Northern Cyprus. International Journal of Contemporary Hospitality Management, 17(4), 315-331.

Ladkin, A., \& Juwaheer, T.D. (2000). The career paths of hotel general managers in Mauritius. International Journal of Contemporary Hospitality Management, 12(2), 119-125. 
Langer, G. (2003). A comparison of training activities in the Austrian and German accommodation trade using the Training Activity Degree. International Journal of Tourism Research, 5, 29-44.

Lee-Ross, D. (2005). Perceived job characteristics and internal work motivation: an exploratory cross-cultural analysis of the motivational antecedents of hotel workers in Mauritius and Australia. Journal of Management Development, 24(3), 253-266.

Leopold, J., \& Harris, L. (2009), The Strategic Managing of Human Resources, Harlow, Essex: Prentice Hall Education Ltd.

Lockyer, T. (2005). Understanding the dynamics of the hotel accommodation purchase decision. International Journal of Contemporary Hospitality Management, 17(6), 481492.

Luk, S.T.K., \& Layton, R. (2004). Managing both outcome and process quality is critical to quality of hotel service. Total Quality Management \& Business Excellence, 15(3), $259-278$.

Luoma, M. (2000). Developing people for business success: capability driven HRD in practice. Management Decision, 38(3), 145-153.

Maxwell, G., McDougall, M., \& Clair, S. (2000). Managing diversity in the hotel sector: the emergence of a service quality opportunity. Managing Service Quality, 10(6), 367373.

McCracken, M., \& Wallace, M. (2000). Towards a redefinition of strategic HRD. Journal of European Industrial Training, 24(5), 281-290.

Murphy, P.E., \& Price, G.G. (2005). Tourism and sustainable development. In W.F. Theobald, Global Tourism ( $3^{\text {rd }}$ Edition), Burlington: Elsevier, 167-192

National Report (2008). The development of education. Ministry of Education, Culture \& Human Resources, Ebene, Mauritius. 
Neville, S., \& Nishantha, S. (2004). Small island developing states: challenges, prospects and international cooperation. International Research Foundation for Development, Policy Paper (E/CN.17/2004/8).

Nolan, C. (2002). Human resource development in the Irish hotel industry: the case of the small firm. Journal of European Industrial Training, 26(2/3/4), 88-99.

Nolan, C., Conway, E., Farrell, T., \& Monks, K. (2010). Competency needs in Irish hotels: employer and graduate perspectives. Journal of European Industrial Training, 34(5), 432-454.

O’Neill, M.A. (1997). Celebrate and record: investing in people: a perspective from Northern Ireland tourism-part 2. Managing Service Quality, 7(6), 292-300.

Poulston, J. (2008). Hospitality workplace problems and poor training: a close relationship. International Journal of Contemporary Hospitality Management, 20(1), 412-427.

Prayag, G., \& Ryan, C. (2011). The relationship between the push \& pull attributes of a tourist destination: the role of nationality: An analytical qualitative research approach. Current Issues in Tourism, 14(2), 121-143.

Ramos, V., Rey-Maquieira, J., \& Tugores, M. (2004). The role of training in changing an economy specialising in tourism. International Journal of Manpower, 25(1), 55-72.

Roehl, W.S., \& Swerdlow, S. (1999). Training and its impact on organisational commitment among lodging employees. Journal of Hospitality \& Tourism Research, 23(2), 176194.

Ryan, C., \& Cave, J. (2005). Structuring destination image: a qualitative approach. Journal of Travel Research, 44(4), 143-150.

Stepchenkova, S. \& Morrison, A.M. (2008). Russia's destination image among American pleasure travellers: revisiting Echtner and Ritchie. Tourism Management, 29(3), 548560. 
Stepchenkova, S., Kirilenko, A.P., \& Morrison, A.M. (2009). Facilitating content analysis in tourism research. Journal of Travel Research, 47(4), 454-469.

Swanson, R.A. (1996). In praise of the dependent variable. Human Resource Development Quarterly, 7(3), 203-207.

Taylor, R., \& Davies, D. (2004). Aspects of training and remuneration in the accommodation industry: A comparison between Australian and Singaporean providers. Journal of European Industrial Training, 28(6), 466-473.

Tseng, C.C., \& McLean, G.N. (2008). Strategic HRD practices as key factors in organizational learning. Journal of European Industrial Training, 32(6), 418-432.

UN Department of Economic \& Social Affairs (1998). Commission on Sustainable Development ( $6^{\text {th }}$ Session), New York, 13 April to 1 May.

UNDP (2011). Human Development Report [online]. Available at < http://hdr.undp.org/en/media/HDR_2011_EN_Complete.pdf $>$ [accessed on 25 July 2012]

Walton, J. (1999). Strategic Human Resource Development. Harlow, Essex: Financial Prentice Hall Education Ltd.

Watson, S., Maxwell, G.A., \& Farquharson, L. (2007). Line managers' views on adopting human resources roles: the case of Hilton (UK) hotels. Employee Relations, 29(1), 3049.

Woelfel, J. (1998), Catpac User's Manual. (Catpac II, Version 2.0), New York: Rah Press. World Travel and Tourism Council (2010). Country Report on Mauritius. London: WTTC 